\title{
Deep Eutectic Solvent Dyeing of Cellulose Acetate Nanofibers With Disperse Dyes: Kinetics, Isotherm and Thermodynamic Studies
}

\author{
Muhammad Tarique \\ Soochow University
}

Winges Fatima

Soochow University

Faraz Khan Mahar

Soochow University

Min Li

Soochow University

Jing Gu

Soochow University

\section{Farooq Ahmed}

Mehran University of Engineering \& Technology

\section{Zeeshan Khatri}

Mehran University of Engineering \& Technology

Kai Wei ( $\nabla$ weikai@suda.edu.cn )

Soochow University https://orcid.org/0000-0002-6255-192X

\section{Research Article}

Keywords: Deep Eutectic Solvents, Exhaust method, Cellulose acetate, Disperse dyes, Ethylene glycol, Urea.

Posted Date: December 22nd, 2021

DOI: https://doi.org/10.21203/rs.3.rs-1163288/v1

License: (c) (i) This work is licensed under a Creative Commons Attribution 4.0 International License. Read Full License 


\section{Abstract}

Deep Eutectic Solvents (DES) was introduced more than a decade ago and has been used in variety of applications based on their unique chemical and physical properties. Recently, they have shown a considerable attention in various sectors including nanotechnology because they have distinctive features as "New green solvents". Within this scope of work, we introduced choline chloride (CC) as a DES which is nontoxic, inexpensive and has tendency to improve color yield properties of disperse dyes on the nanofibers membrane. Cellulose acetate nanofibers (CANF) were electrospun and dyed with Color Index Disperse Red 277, Color Index Disperse Blue 165:1, and Color Index Disperse Yellow 211 in Choline chloride:Ethylene glycol (CC:EG) media and Choline chloride:Urea (CC:Urea) media by using hightemperature exhaust method. Results revealed that dyeing of CANF by CC:EG media has good color fixation properties than CC:Urea media. The dyed samples were characterized by FTIR and SEM. Further, the thermodynamic, standard affinities, and kinetic parameters have also been analyzed. The proposed dyeing of CANF with DES showed excellent calorimetric properties within a short interval of time as compared to conventional dyeing process.

\section{Introduction}

Based on the current rapid growth in research on nanofibers for apparel use (Ahmed et al. 2017), the researchers focused primarily only on the mechanical and functional properties of the fibers and, to the literature relevant, aesthetic properties have not been investigated to date. Disperse dyes are quite well known because they have an affinity for cellulose acetate polymer (Hussain et al. 2021). Cellulose acetate nanofibers (CANF) have distinct adsorption characteristics and therefore have been considered to be an ideal choice for applications (Cao and Su 2021). In 2013, the pad-dry-bake technique of dyeing of CANF with disperse dyes was firstly reported, an attempt was made to investigate the aesthetic properties of nanofibers. The resulting nanofibers also provided satisfying dyeing results (color yield $(K / S \sim 11)$ at 50 g.L ${ }^{-1}$ dye concentration) (Khatri et al. 2013b). Deep eutectic solvents (DES) are now broadly recognized as a new class of "Green solvents" (Pätzold et al. 2019). In general, DES are a composition of two or more components that are capable of interacting with each other. The idea of DES was firstly proposed by (Abo-Hamad et al. 2015). A eutectic solvent is prepared through the blend of urea and choline chloride (CC) with a 2:1 molar ratio having melting point $133^{\circ} \mathrm{C}$ and $302{ }^{\circ} \mathrm{C}$, respectively. The outcome was a eutectic blend that melts at $12{ }^{\circ} \mathrm{C}$ (Nunes et al. 2019). The expanding interest of DES is credited to their capability to be significantly more environmentally friendly (Fan et al. 2020).

A textile industry utilizes a significant volume of water especially used in its dyeing and finishing operational activities. Considering the wastewater generated from textile industry is referenced as one of the most polluting amounts for all the industrial sectors (Marullo et al. 2020; Pawar and Adivarekar 2020; Zhou et al. 2020). To overcome wastewater problems, CC was used with two different solvents ethylene glycol (EG) and urea to compare the results. Numerous variables, including certain hydrogen bonding, surface tension, viscosity and polarity have been reported to stimulate the reactivity of DES (Pawar et al. 2021). 
In the analysis, after the generation of nanomaterials, dyeing of CANF was done to improve specific properties of nanofibers (Khatri et al. 2013a, 2017). Over the previous two decades, due to its appealing properties, which also include high mechanical, transparency and barrier properties, biodegradability, biorestoration capacity, and large diversity it has been taken into consideration (Ullah et al. 2021). The attempt to analyze the properties by exhaust method was made to approximate the dyeing characteristics of dispersed dyes with DES. The impact of distributed dye exhaustion on the cellulosic substrate is investigated by a variety of factors which includes the most important elements of the sample are: dye bath $\mathrm{pH}$, dyeing temperature, time, and alkali concentration (de Aragão Umbuzeiro et al. 2005). Moreover, theoretically the material to liquor ratio in the experiment should be kept constant to 1:100 and it has been chosen due to the nature of fiber used, because material to liquor ratio plays a vital role to optimize the color yield which saves the chemicals, dyes, water, energy, and other resources (Chequer et al. 2013). The textile industry has been expanded because of the general effectiveness of environmentally friendly disperse dyes (Al-Etaibi and El-Apasery 2020; Khan et al. 2021). In particular, disperse dyes have attributes of being soluble in even less water and therefore must be milled to a very limited precise size during dyeing and dispersion in water using a surfactant (dispersing agent), or otherwise a carrier must be applied during dyeing (Carneiro et al. 2010; Khatri et al. 2011; Filho et al. 2020). Furthermore, to expand more deeply, the study of DES with EG and urea are examined by exhaust method for dyeing of CANF with Color Index (Cl) Disperse Blue 165:1, Cl Disperse Yellow 211 and $\mathrm{Cl}$ Disperse Red 277. This paper aims to show the capability of disperse dyes used with green solvents to check the dye adsorption into the core of nanofibers under normal conditions of pressure and temperature, in an attempt to get high dye uptake; consequently, the amount of dye, wastewater was reduced and this reduces environmental hazards.

\section{Materials And Methodology}

Cellulose acetate $(\mathrm{CA})$ (average $\mathrm{Mw}=30 \mathrm{kDa}$ ) was purchased from Sigma-Aldrich Chemical Company was used without additional purification. Three commercials disperse dyes were used namely $\mathrm{Cl}$ Disperse Blue 165:1, CI Disperse RED 277 and CI Disperse Yellow 211 (Fig. 1), supplied by Huntsman, CC (obtained from SCR company), EG and Urea both (obtained from Sigma-Aldrich chemical company) were also used. As in Fig. 1 it can be clearly seen the chemical structure of dyes used.

\subsection{Preparation of CANF}

CANF were electrospun through electrospinning (Tong Li Tech, TL-PRO-BM) as it can be seen in Fig. 2. Using the electrospinning method, a 17\% CA solution by weight prepared in acetone/dimethyl formamide (DMF) with a ratio of 2:1 by weight was directly electrospun. A $20 \mathrm{ml}$ syringe with a stainless steel needle (diameter $22 \mathrm{~mm}$ ) was used for electrospinning, a positive electrode was attached to the metallic tip of the syringe, and a negative electrode was attached to an aluminum foil-wrapped rotating stainless steel drum. From the tip to the rotating drum (speed $150 \mathrm{rpm}$ ), a distance of $14 \mathrm{~cm}$ was set and $16 \mathrm{kV}$ was applied. At $27-29^{\circ} \mathrm{C}$ under $42-44 \%$ relative humidity, the nanofiber web was fabricated. The polymer 
solution was fed at $0.10 \mathrm{~mL} \cdot \mathrm{h}^{-1}$ during electrospinning, regulated by a digital syringe pump (Tong Li Tech, TL-F6). The resulting nanofibers were obtained from aluminium foil and then air dried for 24 hours.

\subsection{Preparation of deep eutectic media for dyeing of CANF}

As reported to the previous methods the DES were prepared with slight changes (Pawar et al. 2021). The CC, EG and urea were selected as a basic material. EG and urea both separately mixed with CC at a magnetic stirring with a specific molar ratio 1:2 respectively until a homogenous mixture of a solution was formed. Furthermore, three disperse dyes as mentioned above, were added in both media solutions CC:EG and CC:Urea respectively. The homogeneous solution was used as a green media to dye CANF.

In Fig. 3, it can be observed the dye adsorption process. CANF nanofibers samples were added in the dye solution of both media. Dye molecules were penetrated into the nanofibers and very less amount of dye was required after the process.

\subsection{Dyeing of CANF in deep eutectic media}

Nanofibers web specimens were dyed by exhaust method using a liquor-to-good ratio 1:100 in glass tubes and all tubes were added into the stainless-steel jar followed by heating at high temperature on exhaust machine (High Temperature dyeing machine GT-D15) within time and temperature control precision. As dyeing of CANF in deep eutectic media CC:EG and CC:Urea was carried out at different parameters. Deep eutectic dyeing has been performed to analyze the effect of time (5 - $30 \mathrm{~min})$, the effect of temperature $\left(35-80^{\circ} \mathrm{C}\right)$, and dye concentration $(1 \%, 2 \%, 3 \%, 4 \%$ and $5 \%$ of fabric weight). We used three samples per assay. The samples were then manually washed by cold water and then dried in an oven under temperature of $70^{\circ} \mathrm{C}$ for $15 \mathrm{~min}$ and then air dried for 3-4 hours at room temperature. After this temperature conditions, the weight of the nanofibers have no changes anymore. The nanofibers were dried. The concentration of dye in the bath was analyzed before and after dyeing using UV-vis spectrophotometer (Perkin Elmer USA, Lambda 25). The absolute decrease in the amount of dye in the bath was observed as the amount of dye fixed on the nanofibers.

\subsection{Chemical structures and Morphology}

Color yields $(K / S)$ value and CIE $L^{*} a^{*} b^{*} C^{*}$ and $h^{\circ}$ organizes at the most extreme assimilation crest were estimated on a UV-vis spectrophotometer [settings: $8.4 \mathrm{~mm}$ sample aperture, illuminate D65, ultraviolet (UV) included, the specular components included reflectance mode and 1964 [10 CIE supplementary standard observer. The color yield after flushing was acquired as the last shading yield. The nanofibers tests were collapsed twice to acknowledge four thicknesses when displayed to the spectrophotometer for shading estimation. The color fastness to washing [ISO 105-C10:2006], hot pressuring [ISO 105-X11] and light [ISO 105-B02] were performed on dyed samples.

The chemical structure of CANF was analyzed before and after dyeing using Fourier Transform Infrared (FTIR) spectroscopy (IR Prestige-21 by Shimadzu, Japan). All CANF samples of $5 \mathrm{mg}$ were ground with $0.1 \mathrm{KBr}$ and pressed into a pellet, measuring the IR transmission. It was carried out in a wave number range of $4000-600 \mathrm{~cm}^{-1}$ with a resolution of $4 \mathrm{~cm}^{-1}$ and the addition of 128 scans under ambient 
conditions. The physical appearance of dyed and undyed CANF webs was analyzed in a Hitachi S-3000N Scanning electron microscope (SEM) with accelerating voltage of $20 \mathrm{kV}$ and average magnification of x10000.

\section{Results And Discussion}

\subsection{Optimization of dyeing parameters and their effect on calorimetric properties}

The effect of temperature on dyeing in CC:EG and CC:Urea media was observed in the range from $35^{\circ} \mathrm{C}$ to $80^{\circ} \mathrm{C}$ and the results are presented in Fig. $4(\mathrm{a} \& \mathrm{~b})$ respectively. The results show that, the value of color strength increases with increasing dyeing temperature, and the maximum color strength was observed at $75^{\circ} \mathrm{C}$ and it remained same above $75^{\circ} \mathrm{C}$ for all dyes. The effect of dyeing temperature could be attributed to the diffusion of dye molecules towards fiber matrix at higher temperature, and it achieves equilibrium at $75^{\circ} \mathrm{C}$ (Mahar et al. 2017). The color strength value of $\mathrm{Cl}$ Disperse Red 277 dye is higher than $\mathrm{Cl}$ Disperse Blue 165:1 dye and CI Disperse Yellow 211 dye. The rate of dye diffusion depends on the size of dye molecules, consequently the value of color strength of dye increases (Khatri et al. 2014). The higher

color strength of $\mathrm{Cl}$ Disperse Red 277 dye could be attributed to smaller size of its molecules compared to CI Disperse Blue 165:1 dye and CI Disperse Yellow 211 dye. Further, from the above results it could be observed that, the media of dye bath has an effect on color strength value. The results show that, CC:EG media has higher values than CC:Urea media. The variation in results of both media is due to their different molar extinction coefficient, affinity, and reactivity (Mahar et al. 2017). The CC:EG media contains EG which has higher affinity and reactivity than urea that is contained in CC:Urea media, therefore, CC:EG media has higher results than CC:Urea media (Tang et al. 2015).

The effect of dyeing time in CC:EG media and CC:Urea media was observed for 5 minutes to 30 minutes with time interval of 5 minutes and, the results are presented in Fig. $5(a \& b)$ respectively. As the dyeing time increases, the color strength value also increases for all dyes, and the maximum values were observed at the dyeing time of 30 minutes. However, for the prolonged dyeing, the results remained same, and this effect could be attributed to dyeing equilibrium in 30 minutes (Mahar et al. 2017).

\subsection{Optimization of dye up-take properties}

Due to substantial dye adsorption and efficient dyeing of CANF at $75^{\circ} \mathrm{C}$, by analyzing the study of comparison with CC:EG media and CC:Urea media to enhance optimum dyeing time to achieve better results as shown in Fig. 6 ( $a \& b)$. Moreover, the depth of color per amount of dye in the fiber shows the more percent of dye take up by the nanofiber. The temperature helps to open the cores of nanofibers and provides the path to the particles of dyes to attain strong attachments to the fiber due to the effect of DES in both media, which opens the internal cores of fiber because it intakes more dyes. Firstly, the three $\mathrm{Cl}$ Disperse Blue 165:1, CI Disperse Yellow 211 and CI Disperse Red 277 shades dyes were used to analyze the study of dyeing with CC:EG media and CC:Urea media. To investigate the build-up property of each 
dye were examined separately under the same dye concentration $(1 \%, 2 \%, 3 \%, 4 \%$ and $5 \%)$ at optimized parameters as mentioned above. Furthermore, the dye concentration 3-5\% were having almost same color shades to washing fastness with excellent dye up take. This effect could be attributed to the saturation of pores in the fiber matrix (Mahar et al. 2017). Further, we observed a slight difference in both media, the CC:EG media has higher results than CC:Urea media. The effect of concentration has direct effect on composition of media (Khatri et al. 2014).

\subsection{Comparison of color yield between CC:EG and CC:Urea media}

The results of deep eutectic dyeing performed with CC:EG media demonstrates higher color yield than dyeing performed with CC:Urea media for all dyes as it is shown in Fig. 7. Color yield of CANF dyed with CI Disperse Blue 165:1, CI Disperse Yellow 211 and CI Disperse Red 277 through CC:EG media indicates higher color shades than CANF dyed with CC:Urea media. Furthermore, for deeply analyze the dyes takeup by the CANF under same conditions with different solvents by exhaust method. Herein, as an attempt, CI Disperse Red 277 with CC:EG media and CI Disperse Red 277 with CC:Urea media shows better color yield than CI Disperse Blue 165:1 and CI Disperse Yellow 211 under both media. The color yield of CANF dyed with CC:EG media shows better shade. For EG, there is no requirement of water because EG itself in the liquid form. Due to this property of EG it has good solubility ratio with dyes which analyzed during the preparation of solution.

\subsection{Dye adsorption isotherm \\ 3.4.1 Standard affinity and the partition coefficient}

The equilibrium partition coefficients $(K)$ of the dye between the bath and the nanofibers were determined according to Eq. (1). Where, ' $\mathrm{C}_{\mathrm{b}}$ ' $(\mathrm{mg} / \mathrm{L})$ and ' $\mathrm{C}_{\mathrm{f}}$ ' $(\mathrm{mg} / \mathrm{L})$ are the amount of dye in dye bath before and after dyeing, respectively. It can be observed in Fig. 8 (a) the dye partition coefficient increased with the dyeing temperature in both media. The partition coefficient of both media increased as the temperature increased. Since, the nanofibers dye adsorption is an endothermic reaction. The results in Fig. 8 (b) show higher partition coefficient in CC:EG media than the CC:Urea media. This difference is due to chemical composition of media and their interaction with dye molecules. Further, the standard affinity $\left(-\Delta \mu^{\circ}\right)$ of dye in both media was calculated by Eq. (2) at different temperatures.

$$
K=\frac{C f}{C b}
$$

$$
-\Delta \mu^{\circ}=R T \ln \left(\frac{C_{f}}{C_{b}}\right)=R T \ln K
$$


Where, ' $-\Delta \mu^{\circ \prime}(\mathrm{cal} / \mathrm{mol})$ is the affinity of dye molecules to the CANF, ' $R$ ' and ' $T$ ' are the gas constant $(1.9872 \mathrm{cal} / \mathrm{mol} . \mathrm{K})$, and the absolute temperature $(\mathrm{K})$, respectively. The calculated values are shown in Table. (1), which show that the standard affinity increases with increasing temperature. Further, it shows that the standard affinity of dye in CC:EG media is higher than CC:Urea media. This finding shows that the dye tendency in CC:EG media is higher than CC:Urea media due to higher reactivity of EG in CC:EG media (Song and StJohn 2004).

Table 1 The partition coefficient $(K)$ and the standard affinity $\left(-\Delta \mu^{\circ}\right)$ of both media

\begin{tabular}{|lllll|}
\hline \multirow{2}{*}{ Temperature (Kelvin) } & \multicolumn{2}{l}{ (CC:EG) media } & \multicolumn{2}{l|}{ (CC:Urea) media } \\
\cline { 2 - 5 } & $\mathrm{K}$ & $-\Delta \mu^{\circ}(\mathrm{cal} / \mathrm{mol})$ & $\mathrm{K}$ & $-\Delta \mu^{\circ}(\mathrm{cal} / \mathrm{mol})$ \\
\hline 308 & 0.25 & -669.369 & 0.15 & -1056.87 \\
\hline 318 & 0.45 & -126.235 & 0.3 & -533.008 \\
\hline 328 & 0.65 & 401.6633 & 0.45 & -130.205 \\
\hline 338 & 0.82 & 1013.878 & 0.65 & 413.9092 \\
\hline 348 & 0.83 & 1091.567 & 0.75 & 756.2996 \\
\hline 353 & 0.83 & 1107.251 & 0.76 & 804.9214 \\
\hline
\end{tabular}

\subsubsection{Enthalpy change and entropy change}

The enthalpy is the second thermodynamic quantity which is important in describing a dyeing process that is the change in enthalpy of the system when adsorption takes place. According to the ClausiusClapeyron Eq. (2), the slope of Eq. (3) shows the dyeing enthalpy $\left(\Delta \mathrm{H}^{\circ}\right)$ could be simply determined by plot of ' $-\Delta \mu^{\circ} / T^{\prime}$ ' versus ' $1 / T^{\prime}$. The results presented in Fig. $8(\mathrm{c})$ that shows the linear relationship between ' $-\Delta \mu^{\circ} / T^{\prime}$ versus ' $1 / T^{\prime}$ ' on enthalpy change $\left(\Delta H^{\circ}\right)$. The enthalpy change is described in Table. 2 which shows that enthalpy of dye in CC:EG media is higher than CC:Urea media. It is concluded that the dye molecules have high potential affinity towards nanofibers in CC:EG media. Similarly, the entropy change of dye in both media was calculated by Eq. (4). Fig. 8(d) demonstrates the relationship between ' $-\Delta \mu^{\prime \prime}$ and ' $T$ ' on entropy change. The summarized results in Table. 2 indicate that the entropy changes of dye in CC:EG media is lower than in CC:Urea media.

$$
\left(\frac{-\Delta \mu^{\circ}}{T}\right)=\frac{\Delta \mathrm{H}^{\circ}}{T}+C
$$

3

$-\Delta \mu^{\circ}=\mathrm{T} \Delta \mathrm{S}^{\circ}-\Delta \mathrm{H}^{\circ}(4)$ 
Where, ' $\Delta \mathrm{H}^{\circ}$ ' and ' $\mathrm{C}$ ' are the heat of dyeing $(\mathrm{cal} / \mathrm{mol})$ known as enthalpy and the integration constant, respectively.

Table 2

The enthalpy change $(\mathrm{H})$ and the entropy change $(\mathrm{S})$

of both media

\begin{tabular}{|lll|}
\hline$\Delta \boldsymbol{\Delta}$ & & \\
\hline Parameters & CC:EG media & CC:Urea media \\
\hline$\Delta \mathrm{H}^{\circ}(\mathrm{cal} / \mathrm{mol})$ & 13424 & 14206 \\
\hline$\Delta \mathrm{S}^{\circ}(\mathrm{cal} / \mathrm{mol} . \mathrm{K})$ & 41.3 & 42.6 \\
\hline
\end{tabular}

\subsubsection{Optimization of dyeing time and co-efficient of diffusion}

In this study, the effect of dyeing time was observed at different time intervals keeping the temperature at $75^{\circ} \mathrm{C}$ and dye concentration at $3 \%$. It was observed in Fig. 9 (a) that the dyeing of nanofibers in both media achieved equilibrium after 30 min of dying. In addition, the Hill's equation was used to calculate the coefficient of dye diffusion into different nanofibers. According to Hill's equation, the diffusion coefficient (D) was calculated by plotting ' $C_{t} / C_{n}$ ' versus ' $t$ ' $1 / 2$ ' as presented in Fig. 9 (b) for the early stage of dyeing, using Eq. (5).

$\left(\frac{t}{C n}\right)=4\left(\frac{\mathrm{Dt}}{\pi \mathrm{r}^{\wedge} 2}\right)^{1 / 2}$

Where, ' $\mathrm{C}_{t}$ ' $(\mathrm{mg} / \mathrm{L})$ is the concentration of dye at the reaction time ' $\mathrm{t}$ ' and ' $\mathrm{C}_{n}$ ' $(\mathrm{mg} / \mathrm{L})$ is the initial concentration of dye, and ' $r$ ' $(\mathrm{cm})$ is the radius of the cylindrical nanofibers. The diffusion coefficient of dye in both media was compared. The dyeing rates were obtained at $75^{\circ} \mathrm{C}$. It was observed that the diffusion coefficient of dye in CC:EG media was greater than in CC:Urea media.

\subsubsection{Dye sorption isotherm for dyeing of nanofiber in deep eutectic media}

To investigate effect of dye concentration on color buildup properties of nanofibers, the dyeing was carried out in (CC:EG) and (CC:Urea) media at different concentration. In Fig. 10 (a) the results show higher color build up in CC:EG media as compared to CC:Urea media. It also indicates that with increasing dye concentration, the color strength also increases. Further, the application of the adsorption capacity for dye on CANF in both media and their binding affinities was calculated using two isotherms namely, Langmuir and Freundlich as given in the Eq. (6) and Eq. (7) respectively.

$$
\frac{C_{e}}{q_{e}}=\frac{1}{q_{m} K_{L}}+\frac{C_{e}}{q_{m}}
$$




$$
\log q e=\frac{1}{n} \log C_{e}+\log K_{f}
$$

7

Where, 'Ce' $(\mathrm{mg} / \mathrm{g})$, is the equilibrium concentration of all dyes used in the solution ' $\mathrm{q}_{\mathrm{e}}{ }^{\prime}(\mathrm{mg} / \mathrm{g})$ is the equilibrium adsorption capacity of CANF, and ' $\mathrm{K}_{\mathrm{L}}$ ' $(\mathrm{L} / \mathrm{mg})$ is the equilibrium constant of Langmuir, ' $\mathrm{q}_{\mathrm{m}}$ ' $(\mathrm{mg} / \mathrm{g})$ is the maximum adsorption capacity when monolayer coverage reaches by adsorption. ' $1 / \mathrm{n}$ ' is the adsorption index that determines the degree of adsorbent surface heterogeneity, and the value of ' $1 / n^{\prime}$ always lies between 0 and 1 in all cases. ' $K_{F}$ ' $(\mathrm{mg} / \mathrm{g}) .(\mathrm{L} / \mathrm{mg})^{\wedge} 1 / \mathrm{n}$ is the Freundlich constant, which represents adsorption capacity. The adsorption behavior of dye in both media was observed by Freundlich and Langmuir isotherm, Fig. 10(b) shows the fitting of Langmuir isotherm model by plotting curve between $\mathrm{Ce}$ and $\mathrm{Ce} / \mathrm{Qe}$, and Fig. 10(c) indicates the fitting of Freundlich isotherm by plotting curve between Logqe and LogCe. The calculated values are summarized in Table. 3, the regression coefficient $\left(R^{2}\right)$ for the Freundlich isotherm is higher than the Langmuir model, which demonstrated the adsorption behavior of dye favors the Freundlich isotherm. It means the dyeing mechanism is heterogeneous multiyear adsorption, and thecalculated maximum adsorption capacity $\left(\mathrm{q}_{\mathrm{m}}\right)$ for CC:EG is higher than that of CC:Urea media.

Table 3

Langmuir and Freundlich isotherms of both media

\begin{tabular}{|llllllll|}
\hline Media & \multicolumn{3}{l}{ Isotherm } \\
\cline { 2 - 7 } & \multicolumn{2}{l}{ Langmuir } & \multicolumn{4}{l}{ Freundlich } \\
\hline & $\mathrm{q}_{\mathrm{m}}$ & $\mathrm{R}^{2}$ & $\mathrm{~K} \mathrm{~L}$ & $1 / \mathrm{n}$ & $\mathrm{R}^{2}$ & $\mathrm{~K}_{\mathrm{F}}$ \\
\hline CC:EG & 454 & 0.98 & 0.0052 & 0.712 & 0.99 & 5.26 \\
\hline CC: Urea & 357 & 0.98 & 0.0051 & 0.681 & 0.99 & 13.6 \\
\hline nical structures of & dyed and undyed CANF
\end{tabular}

In Fig. 11(a) The FTIR spectra of pure CANF and dyed CANF with three different disperse dyes in CC:EG media is presented. In the FTIR spectra the CANFs exhibited an absorption band of $\mathrm{OH}$ group stretching at 3500, and also it showed some characteristics peaks at 1855, 1300 and $1235 \mathrm{~cm}^{-1}$ due to stretching of $\mathrm{C}=\mathrm{O}, \mathrm{C}-\mathrm{CH}_{3}$, and $\mathrm{C}-\mathrm{O}-\mathrm{C}$, respectively (Aboamera et al. 2018). Further, after dyeing CANF with disperse dyes in CC:EG media, the FTIR spectra showed a new peak at $1340 \mathrm{~cm}^{-1}$ which is corresponding to CN stretching. This new peak could be attributed to $\mathrm{CN}$ group of disperse dyes. Similarly, in Fig. 11(b) the FTIR spectra of pure CANF and dyed CANF with same three dyes in CC:Urea media is presented, It was observed that the FTIR spectra of pure CANF and dyed CANF in CC:Urea media was same as it was observed in Fig. 11(a) for CC:EG media. It could be said that dyeing of CANF in DES do not have any effect on chemical properties of CANF. 


\subsection{Physical morphology of nanofibers}

The physical properties of pure undyed CANF Fig. 12 ( $a$ to b), dyed CANF Fig: 12 (c to h) and Fig. 13 (i-n) shows SEM images dyed ( $3 \%$ dye, $75^{\circ} \mathrm{C}, 30 \mathrm{~min}$ ) nanofibers and their diameter distribution histograms. The images declared that even after dyeing the morphology of dyed CANF with no changes in the morphology of CANF and remained symmetrical to that undyed CANF as above. The dyed nanofibers reveal better resistance to wet and heat resistance during dyeing. Even after dyeing carried by exhaust dyeing method, the CANF remained smooth and uniform.

\subsection{Color fastness}

The color fastness to washing (shade change and staining) and light fastness tests were analyzed on dyed CANF with CC:EG media and CC:Urea media with dye concentration of $3 \%$ of $\mathrm{Cl}$ Disperse Red $277, \mathrm{Cl}$ Disperse Yellow 211 and $\mathrm{Cl}$ Disperse Blue $165: 1$ at $75{ }^{\circ} \mathrm{C}$ for 30 mins and the colorfastness results have been shown in Table 1. Furthermore, the staining and washing fastness test for $\mathrm{Cl}$ Disperse Red 277, $\mathrm{Cl}$ Disperse Yellow 211 and CI Disperse Blue 165:1 of CC:EG media shows better color shades and attained maximum ratings than $\mathrm{CC}$ :Urea media. Hence, it indicates no color bleeding with better color fixation. The staining of Cl Disperse Red 277, Cl Disperse Yellow 211 and CI Disperse Blue 165:1 with CC:Urea media were observed in comparison with (CC:EG) media has ratings 4/5. Therefore, it declares that $\mathrm{Cl}$ Disperse Red 277, CI Disperse Yellow 211 and CI Disperse Blue 165:1 with CC:EG media and CC:Urea media shows good dye fixation with better color yield. The predictable reason of better fixation of dyes and less color bleeding of CC:EG media in comparison with CC:Urea media is may be due to the inherent stability of the dyes chromogen with EG including CC. The results are given in Table 4 CC:EG media and Table 5 CC:Urea media. The light fastness ratings in all the cases were revealed properly ensuring dark shades in consideration. A slight difference was observed during dyeing process carried out with CC:EG media than CC:Urea media. Apparently, the Cl Disperse Red 277 having good shades than Cl Disperse Yellow 211 and Cl Disperse Blue 165:1 same in case CC:Urea media.

Table 4

Color fastness to light test ISO-BO2 and color fastness to washing test ISO 105-C10:2006 of CC:EG media

\begin{tabular}{|c|c|c|c|c|c|c|c|c|c|}
\hline \multirow[t]{2}{*}{ Dye shade } & \multirow{2}{*}{$\begin{array}{l}\text { Dye } \\
\text { conc. } \\
\text { (\%) }\end{array}$} & \multirow{2}{*}{$\begin{array}{l}\text { Light } \\
\text { fastness (20 } \\
\text { h) }\end{array}$} & \multirow[t]{2}{*}{$\begin{array}{l}\text { Washing } \\
\text { fastness }\end{array}$} & \multicolumn{6}{|c|}{$\begin{array}{l}\text { Washing fastness (staining on } \\
\text { multifiber) }\end{array}$} \\
\hline & & & & CT & $\mathrm{CO}$ & PA & PES & PAC & Wo \\
\hline $\begin{array}{l}\text { Cl Disperse } \\
\text { Red } 277\end{array}$ & 3 & 7 & 5 & 5 & 5 & 5 & 5 & $4 / 5$ & 5 \\
\hline $\begin{array}{l}\text { Cl Disperse } \\
\text { Yellow } 211\end{array}$ & 3 & 7 & 5 & $4 / 5$ & 5 & 5 & 5 & 5 & 5 \\
\hline $\begin{array}{l}\text { Cl Disperse } \\
\text { Blue 165:1 }\end{array}$ & 3 & 7 & 5 & 5 & 5 & $4 / 5$ & 5 & 5 & 5 \\
\hline
\end{tabular}


${ }^{a}$ Dyeing considerations: High-Temperature Exhaust dyeing, Dyeing Temperature $75^{\circ} \mathrm{C}$, dyeing time 30 minutes, dye conc. $3 \%$

${ }^{\mathrm{b}} \mathrm{CT}$ cellulose triacetate, $\mathrm{CO}$ cotton, PA polyamide, PES polyester, PAC polyacrylic, Wo wool.

Table 5

Color fastness to light test ISO-BO2 and color fastness to washing test ISO 105-C10:2006 of CC:Urea media

\begin{tabular}{|c|c|c|c|c|c|c|c|c|c|}
\hline \multirow[t]{2}{*}{ Dye shade } & \multirow{2}{*}{$\begin{array}{l}\text { Dye } \\
\text { conc. } \\
\text { (\%) }\end{array}$} & \multirow{2}{*}{$\begin{array}{l}\text { Light } \\
\text { fastness (20 } \\
\text { h) }\end{array}$} & \multirow[t]{2}{*}{$\begin{array}{l}\text { Washing } \\
\text { fastness }\end{array}$} & \multicolumn{6}{|c|}{$\begin{array}{l}\text { Washing fastness (staining on } \\
\text { multifiber) }\end{array}$} \\
\hline & & & & CT & $\mathrm{CO}$ & PA & PES & PAC & Wo \\
\hline $\begin{array}{l}\text { Cl Disperse } \\
\text { Red } 277\end{array}$ & 3 & 7 & 3 & $4 / 5$ & $4 / 5$ & 3 & 5 & $4 / 5$ & 5 \\
\hline $\begin{array}{l}\text { Cl Disperse } \\
\text { Yellow } 211\end{array}$ & 3 & 6 & 3 & 3 & 3 & $4 / 5$ & $4 / 5$ & 3 & $4 / 5$ \\
\hline $\begin{array}{l}\text { Cl Disperse } \\
\text { Blue 165:1 }\end{array}$ & 3 & 6 & 3 & 5 & 3 & 3 & 3 & 3 & 3 \\
\hline
\end{tabular}

aDyeing considerations: High-Temperature Exhaust dyeing, Dyeing Temperature $75^{\circ} \mathrm{C}$, dyeing time 30 minutes, dye conc. $3 \%$

${ }^{\mathrm{b}} \mathrm{CT}$ cellulose triacetate, $\mathrm{CO}$ cotton, PA polyamide, PES polyester, PAC polyacrylic, Wo wool.

\section{Conclusion}

In this study, we have used green solvents for dyeing of CANF. We took three dyes CI Disperse Blue 165:1, CI Disperse Yellow 211 and CI Disperse Red 277 with two (CC:EG) \& CC:Urea media for dyeing of CANF. The prepared CANF were found smooth before and after dyeing. In this work we compared the results of both media as mentioned above, CC:EG media shows better color yield and light to washing fastness as compared to CC:Urea media. The dyeing parameters were optimized at the dyeing temperature of $75^{\circ} \mathrm{C}$, dyeing time at 30 minutes and dyeing conc. $3 \%$. The dyeing process, based on the positive value of enthalpy, was found to be endothermic in nature. The standard affinity and diffusion coefficient of dyes in CC:EG media towards to CANF were found to be greater than CC:Urea media.

\section{References}

1. Abo-Hamad A, Hayyan M, AlSaadi MA, Hashim MA (2015) Potential applications of deep eutectic solvents in nanotechnology. Chem Eng J 273:551-567. https://doi:10.1016/j.cej.2015.03.091

2. Aboamera NM, Mohamed A, Salama A et al (2018) An effective removal of organic dyes using surface functionalized cellulose acetate/graphene oxide composite nanofibers. Cellulose 25:41554166. https://doi.org/10.1007/s10570-018-1870-8 
3. Ahmed F, Arbab AA, Jatoi AW et al (2017) Ultrasonic-assisted deacetylation of cellulose acetate nanofibers: A rapid method to produce cellulose nanofibers. Ultrason Sonochem 36:319-325. https://doi.org/10.1016/j.ultsonch.2016.12.01

4. Al-Etaibi AM, El-Apasery MA (2020) A comprehensive review on the synthesis and versatile applications of biologically active pyridone-based disperse dyes. Int J Environ Res Public Health 17:4714. https:// doi.org/10.3390/ijerph17134714

5. Cao J, Su E (2021) Hydrophobic deep eutectic solvents: The new generation of green solvents for diversified and colorful applications in green chemistry. J Clean Prod. https://doi.org/10.1016/j.jclepro.2021.127965. 127965 https://

6. Carneiro PA, Umbuzeiro GA, Oliveira DP, Zanoni MVB (2010) Assessment of water contamination caused by a mutagenic textile effluent/dyehouse effluent bearing disperse dyes. J Hazard Mater 174:694-699. https://doi.org/10.1016/j.jhazmat.2009.09.106

7. Chequer FMD, De Oliveira GAR, Ferraz ERA et al (2013) Textile dyes: dyeing process and environmental impact. Eco-friendly Text Dye Finish 6:151-176. https:// doi.org/10.5772/53659

8. de Aragão Umbuzeiro G, Freeman H, Warren SH et al (2005) Mutagenicity evaluation of the commercial product $\mathrm{Cl}$ Disperse Blue 291 using different protocols of the Salmonella assay. Food Chem Toxicol 43:49-56. https://doi.org/10.1016/j.fct.2004.08.011

9. Fan Y, Wu H, Cai D et al (2020) Effective extraction of harmine by menthol/anise alcohol-based natural deep eutectic solvents. Sep Purif Technol 250:117211. https://doi. org/10.1016/j.seppur.2020.117211

10. Filho CMT, Cavalcanti CDÁK, Machado RAF, Marangoni C (2020) Membrane distillation for recovery of textile wastewaters: Determination of operational conditions with PTFE membrane and high dye concentrations. In: AIP Conference Proceedings. AIP Publishing LLC, p 20020 https://doi.org/10.1063/5.0028260

11. Hussain N, Hussain S, Mehdi M et al (2021) Introducing Deep Eutectic Solvents as a Water-Free Dyeing Medium for Poly (1, 4-cYclohexane Dimethylene Isosorbide Terephthalate) PICT Nanofibers. Polymers (Basel) 13:2594. https://doi.org/10.3390/polym13162594

12. Khan SA, Hussain D, Khan TA (2021) Recent Advances in Synthetic Dyes. Innov Emerg Technol Text Dye Finish 91-111. https://doi.org/10.1002/9781119710288.ch3

13. Khatri Z, Ahmed F, Jhatial AK et al (2014) Cold pad-batch dyeing of cellulose nanofibers with reactive dyes. Cellulose 21:3089-3095. https://doi.org/10.1007/s10570-014-0320-5

14. Khatri Z, Ahmed F, Khatri A et al (2017) Screen-printed electrospun cellulose nanofibers using reactive dyes. Cellulose 24:4561-4568. https://doi.org/10.1007/s10570-017-1428-1

15. Khatri Z, Arain RA, Jatoi AW et al (2013a) Dyeing and characterization of cellulose nanofibers to improve color yields by dual padding method. Cellulose 20:1469-1476. https:// doi.org/10.1007/s10570-013-9893-7

16. Khatri Z, Khatri A, Saleem U et al (2013b) Pad dyeing of cellulose acetate nanofibres with disperse dyes. Color Technol 129:159-163. https://doi.org/10.1111/j.1478-4408.2012.00409.x 
17. Khatri Z, Memon MH, Khatri A, Tanwari A (2011) Cold pad-batch dyeing method for cotton fabric dyeing with reactive dyes using ultrasonic energy. Ultrason Sonochem 18:1301-1307. https://doi.org/10.1016/j.ultsonch.2011.04.001

18. Mahar FK, Mehdi M, Qureshi UA et al (2017) Dyeability of recycled electrospun polyethylene terephthalate (PET) nanofibers: Kinetics and thermodynamic study. J Mol Liq 248:911-919. https://doi.org/10.1016/j.molliq.2017.10.116

19. Marullo S, Meli A, Dintcheva NT et al (2020) Environmentally Friendly Eutectogels Comprising Iamino Acids and Deep Eutectic Solvents: Efficient Materials for Wastewater Treatment. ChemPlusChem 85:301-311. https://doi.org/10.1002/cplu.202000017

20. Nunes RJ, Saramago B, Marrucho IM (2019) Surface tension of dl-menthol: octanoic acid eutectic mixtures. J Chem Eng Data 64:4915-4923. https://doi.org/10.1021/acs.jced.9b00424

21. Pätzold M, Burek BO, Liese A et al (2019) Product recovery of an enzymatically synthesized (-)menthol ester in a deep eutectic solvent. Bioprocess Biosyst Eng 42:1385-1389. https://doi.org/10.1007/s00449-019-02125-6

22. Pawar SS, Adivarekar R (2020) A novel approach for dyeing of polyester using non-aqueous deep eutectic solvent as a dyeing medium. Pigment Resin Technol. https://doi.org/10.1108/PRT-09-20190085

23. Pawar SS, Athalye A, Adivarekar RV (2021) Solvent Assisted Dyeing of Silk Fabric Using Deep Eutectic Solvent as a Swelling Agent. Fibers Polym 22:405-411. https:// doi.org/10.1007/s12221021-0142-7

24. Song G, StJohn D (2004) Corrosion behaviour of magnesium in ethylene glycol. Corros Sci 46:13811399. https://doi.org/10.1016/j.corsci.2003.10.008

25. Tang B, Zhang H, Row KH (2015) Application of deep eutectic solvents in the extraction and separation of target compounds from various samples. J Sep Sci 38:1053-1064. https://doi.org/10.1002/jssc.201401347

26. Ullah A, Saito Y, Ullah S et al (2021) Bioactive Sambong oil-loaded electrospun cellulose acetate nanofibers: Preparation, characterization, and in-vitro biocompatibility. Int J Biol Macromol 166:1009-1021. https://doi.org/10.1016/j.ijbiomac.2020.10.257

27. Zhou G, Cao Y, Jin Y et al (2020) Novel selective adsorption and photodegradation of BPA by molecularly imprinted sulfur doped nano-titanium dioxide. J Clean Prod 274:122929. https://doi.org/10.1016/j.jclepro.2020.122929

\section{Figures}


<smiles>CCN(Cc1ccccc1)c1ccc(N=Nc2c(C#N)cc([N+](=O)[O-])cc2[N+](=O)[O-])c(NC(C)=O)c1</smiles>

CI Disperse Blue 165:1

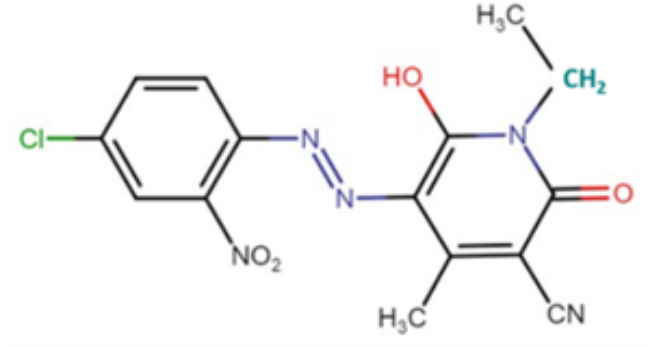

CI Disperse Yellow 211

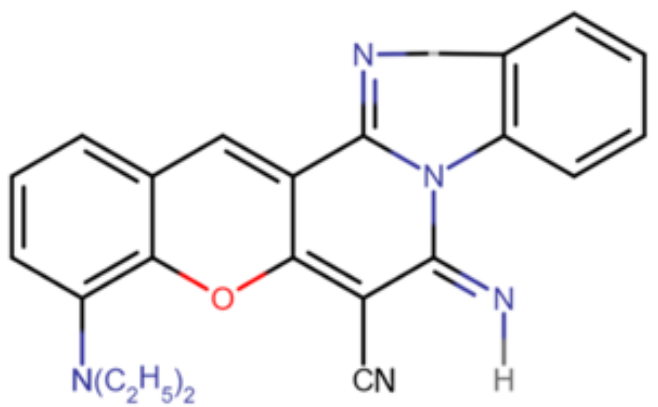

CI Disperse Red 277

\section{Figure 1}

Chemical structure of the used dyes
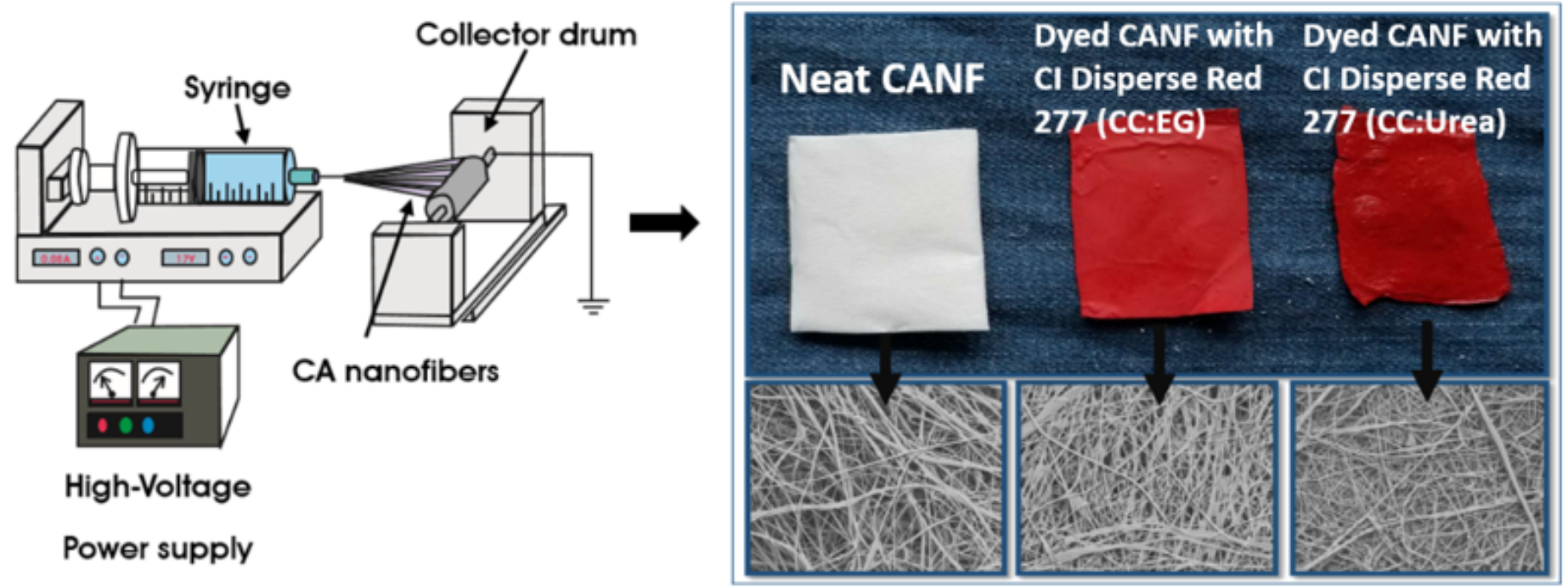

Figure 2

Preparation of Electrospun CANF 


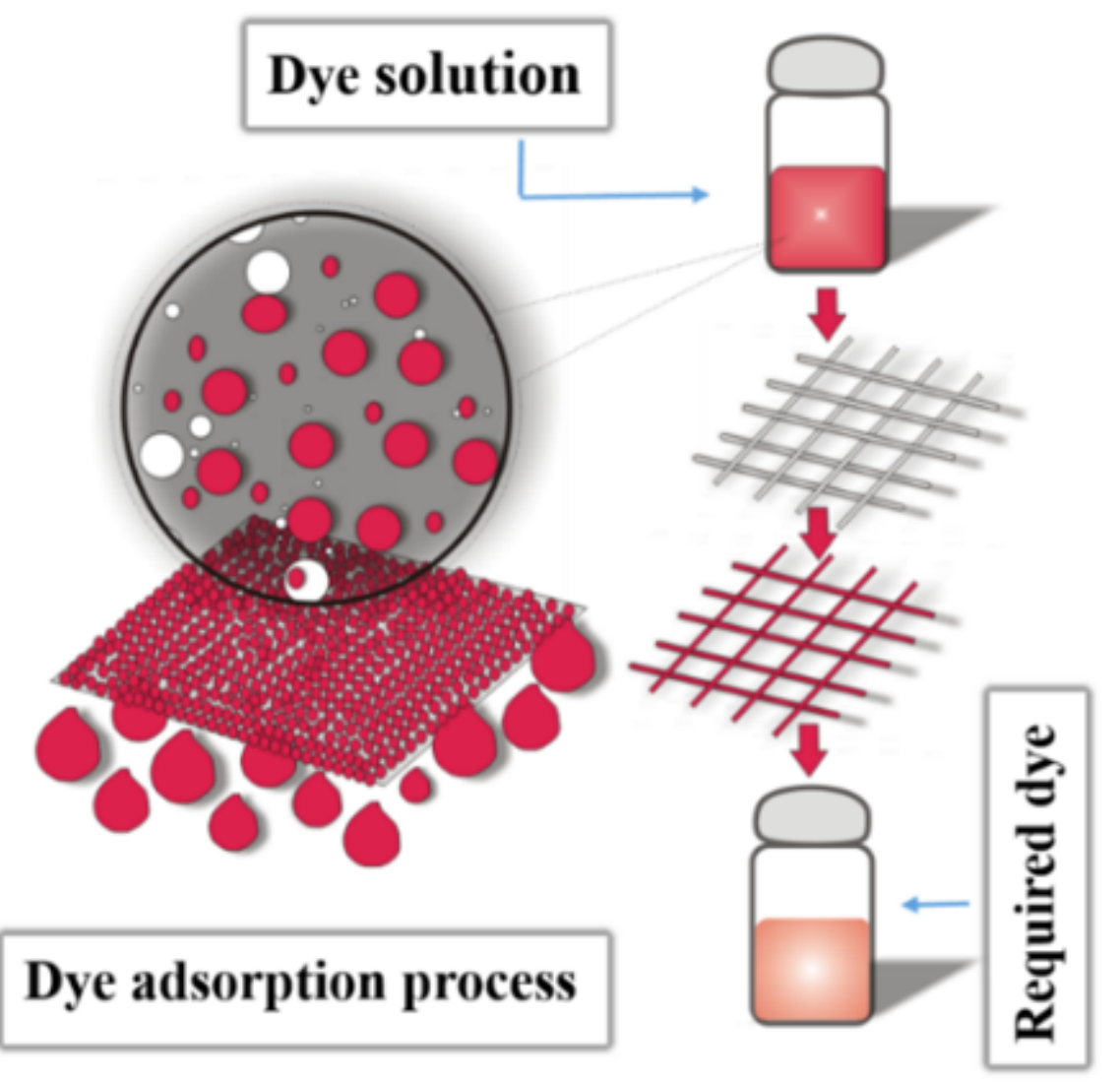

Figure 3

Schematic diagram of CANF dye adsorption process
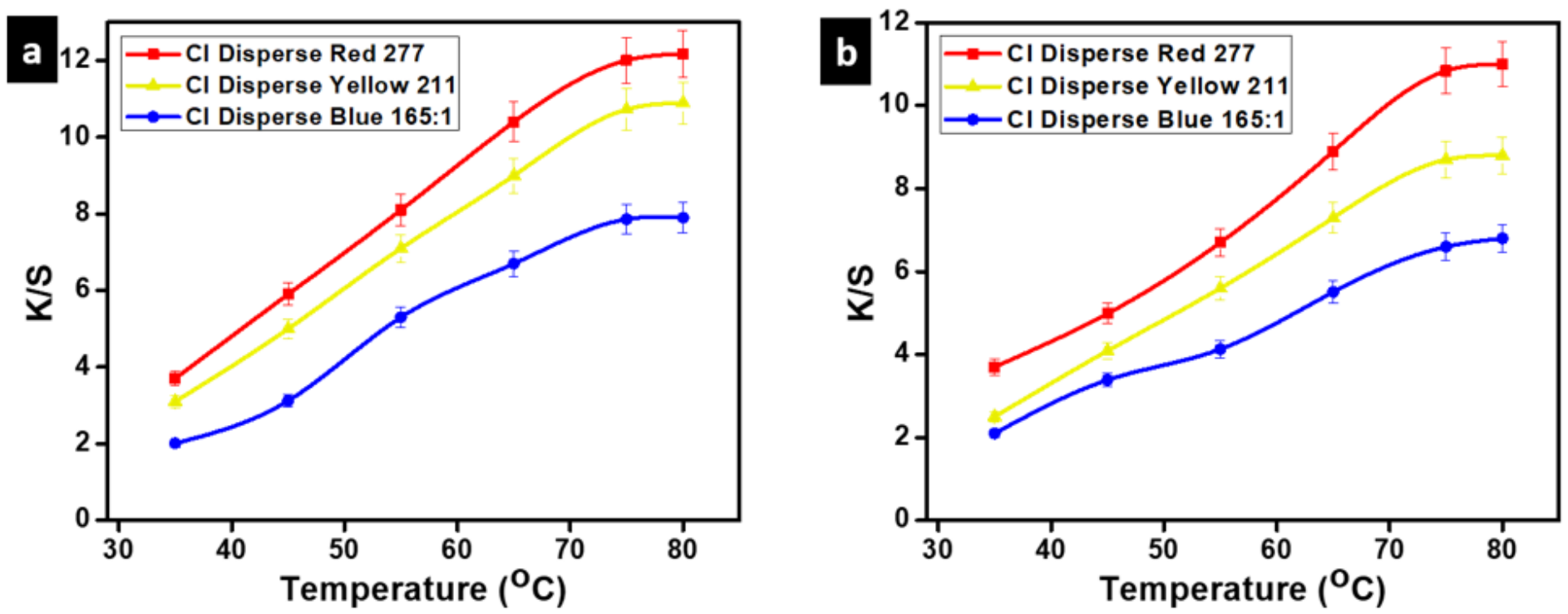

Figure 4 
(a) CC:EG media and (b) CC:Urea media, shows effect of dyeing temperature on color yield (dyeing time 30 min, dye conc. $3 \%$ )
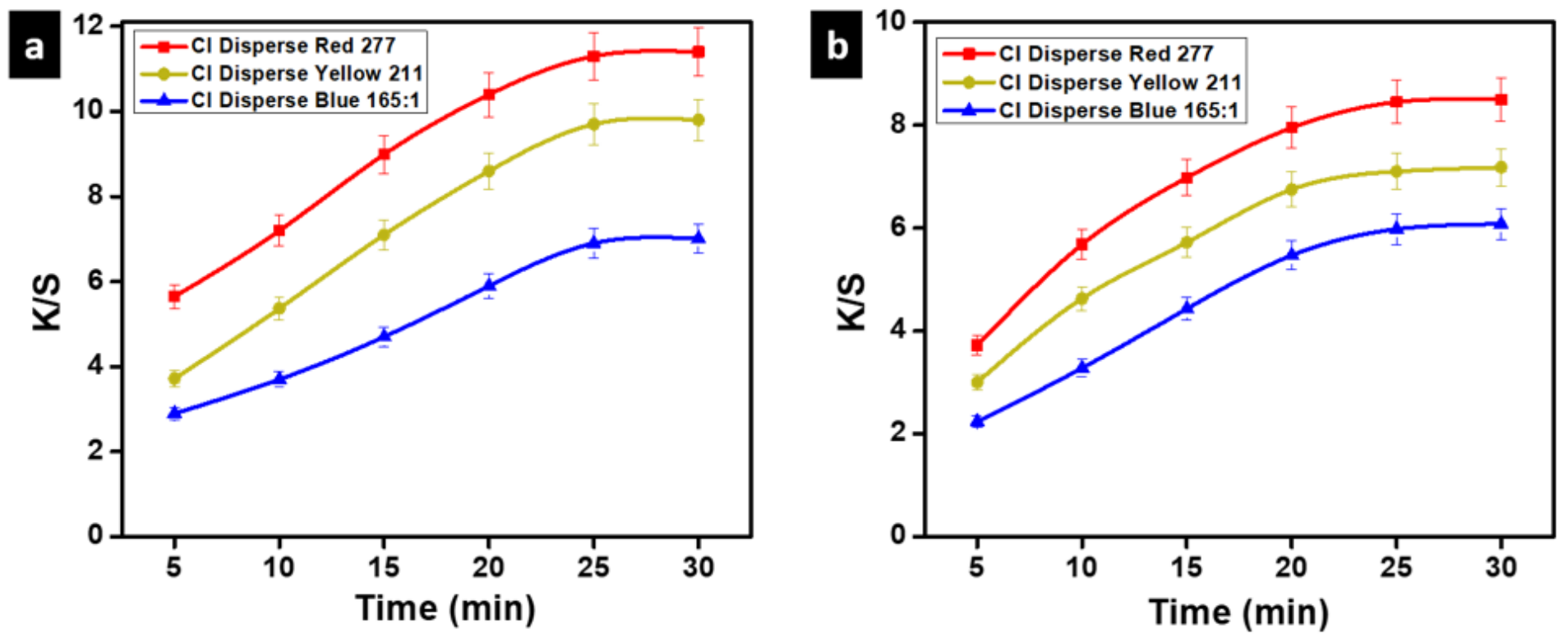

Figure 5

(a) CC:EG media and (b) CC:Urea media, depicts effect of dyeing time on color yield (dyeing temp. $75^{\circ} \mathrm{C}$, dye conc. $3 \%$ )
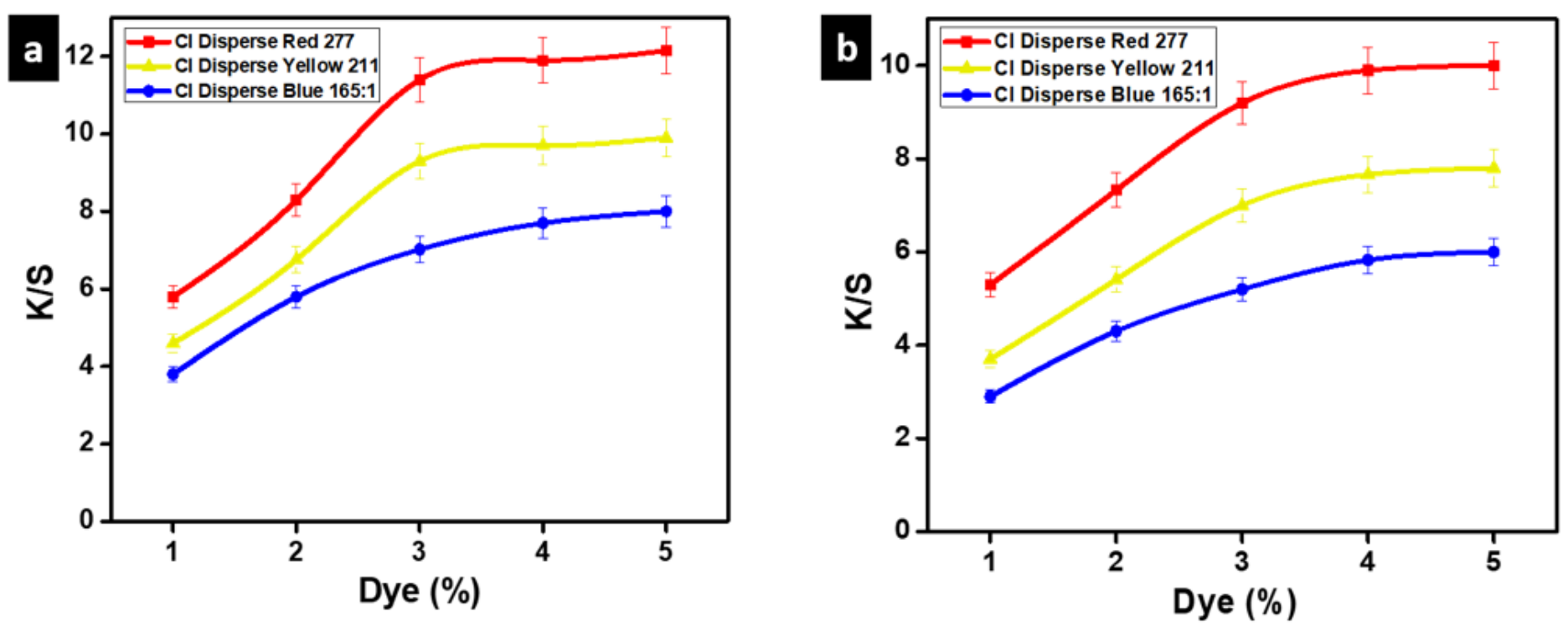

Figure 6

(a) CC:EG media and (b) CC:Urea media, demonstrate effect of dye conc. on color yield (dyeing temp. 75 ${ }^{\circ} \mathrm{C}$, dyeing time $30 \mathrm{~min}$ ) 


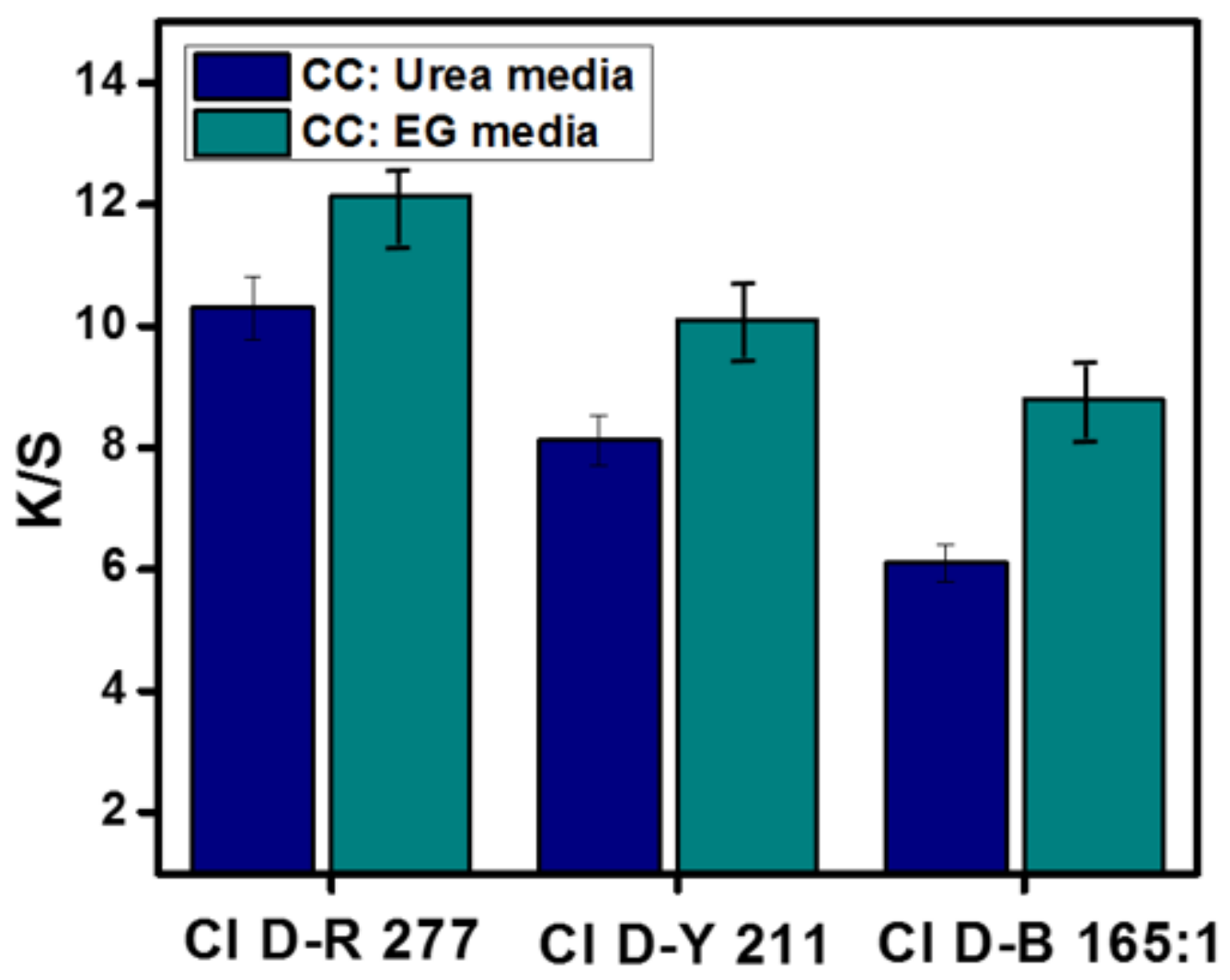

Figure 7

Comparison of color yield CC:EG media and CC:Urea media (CI Disperse RED 277, CI Disperse Yellow 211 and $\mathrm{Cl}$ Disperse Blue $165: 1$ ) (dye conc. $3 \%$, dyeing temp. $75^{\circ} \mathrm{C}$ and dyeing time $30 \mathrm{~min}$ ) 

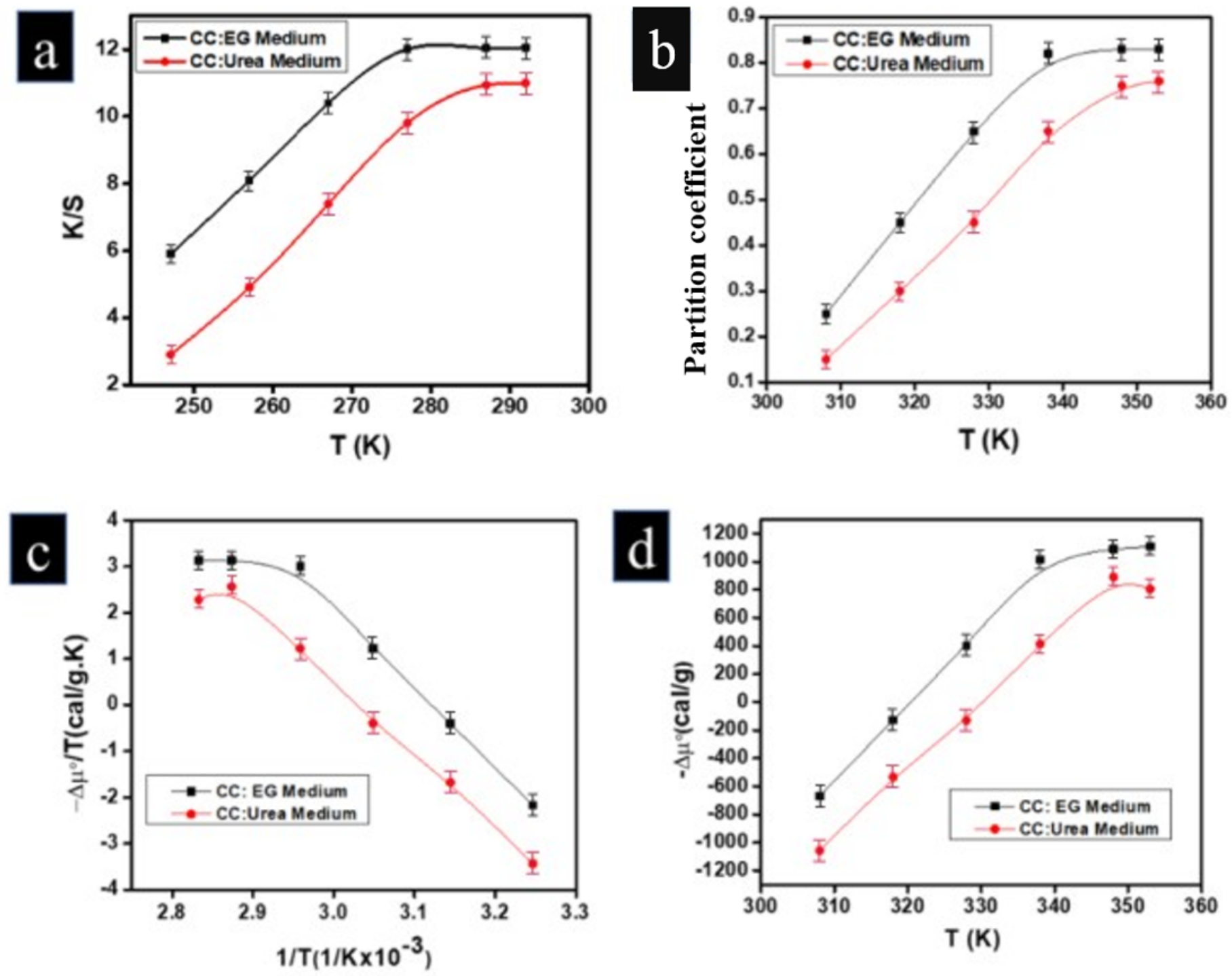

Figure 8

(a) Effect of dyeing temperature on color yield, (b) Partition coefficient against dyeing temperature, (c) relationship between ' $\Delta \mu / \Delta T$ ' and ' $1 / T$ ', (d) relationship between ' $-\Delta \mu$ ' and ' $T$ '. 

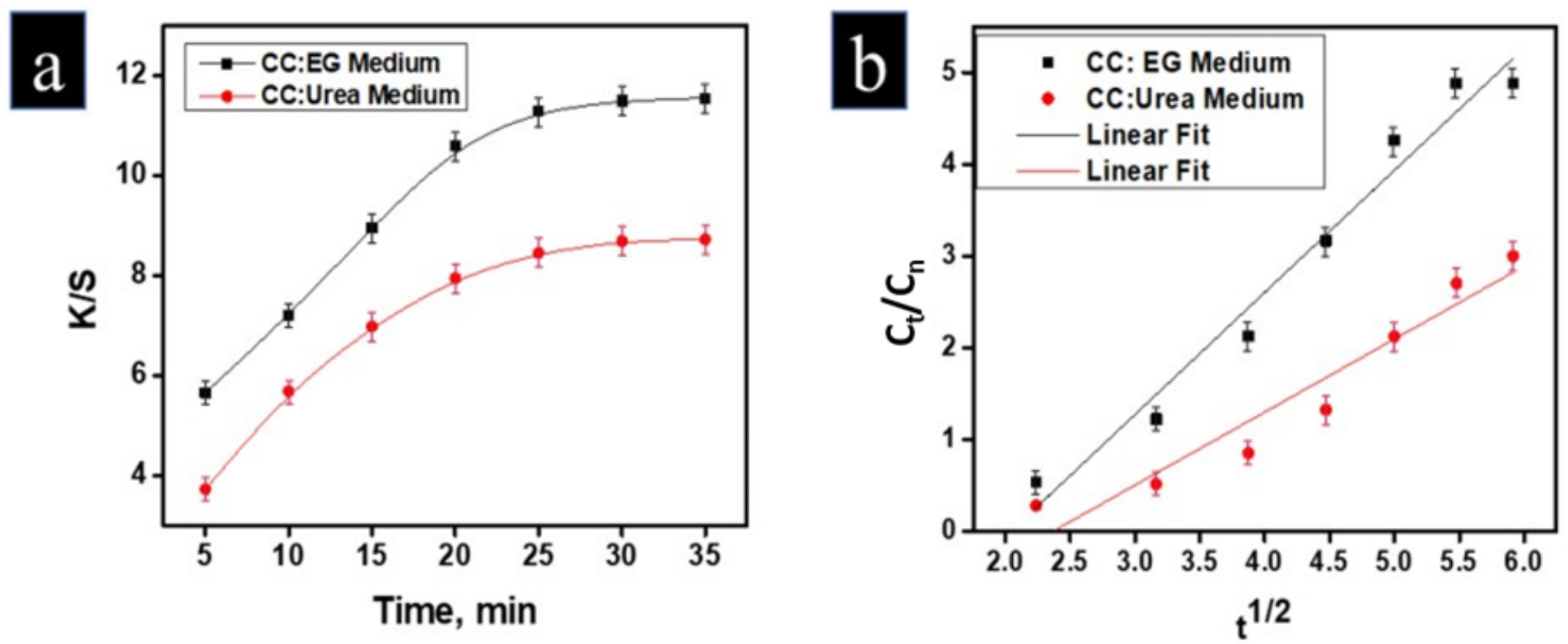

Figure 9

(a) Effect of dyeing time on color yield; and (b) diffusion plots of dye in CC:EG media and CC:Urea media. 

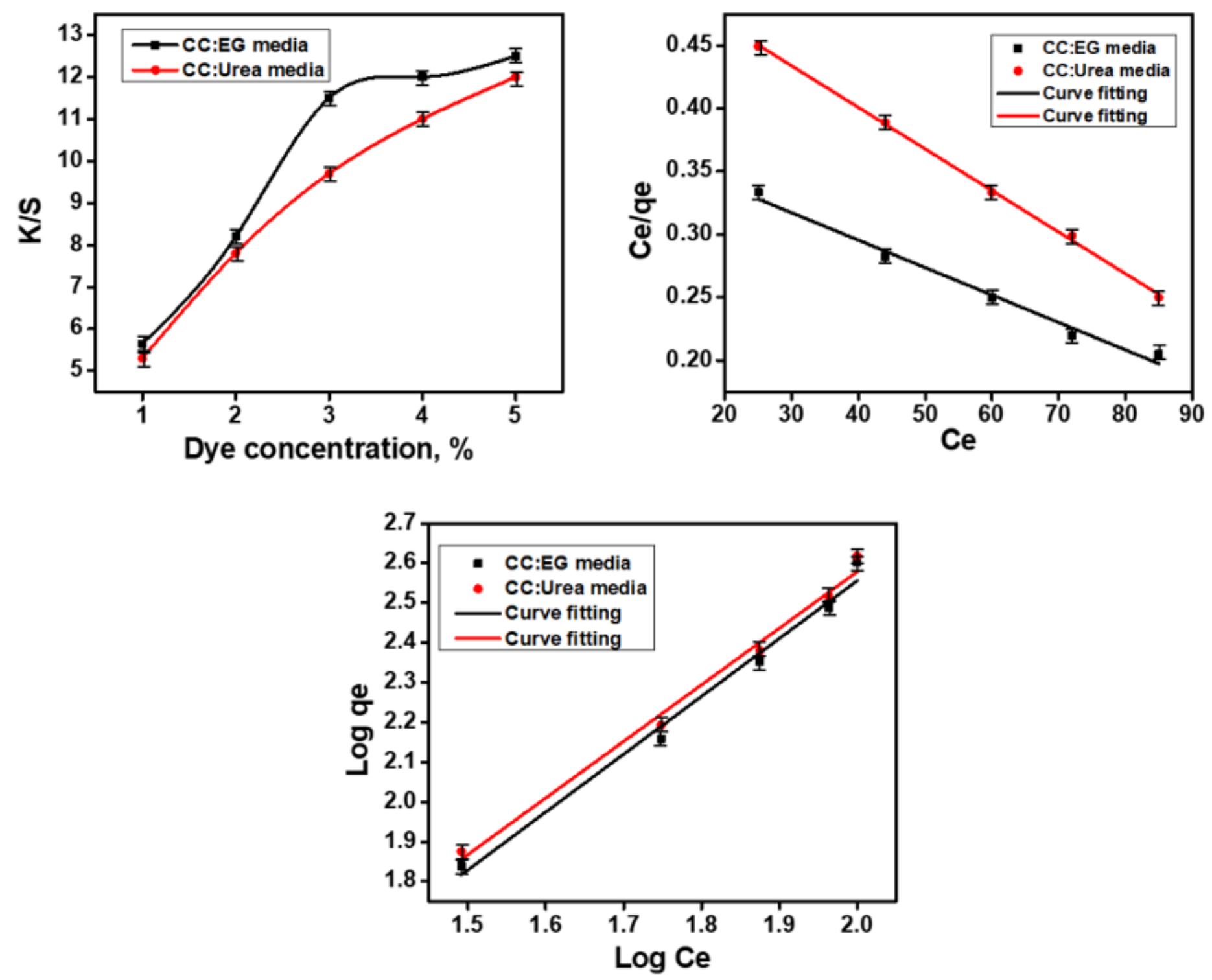

Figure 10

(a) Effect of color yield on dye concerntration (b) Langmuir isotherm, and (c) Freundlich isotherm for CC:EG media and CC:Urea media. 

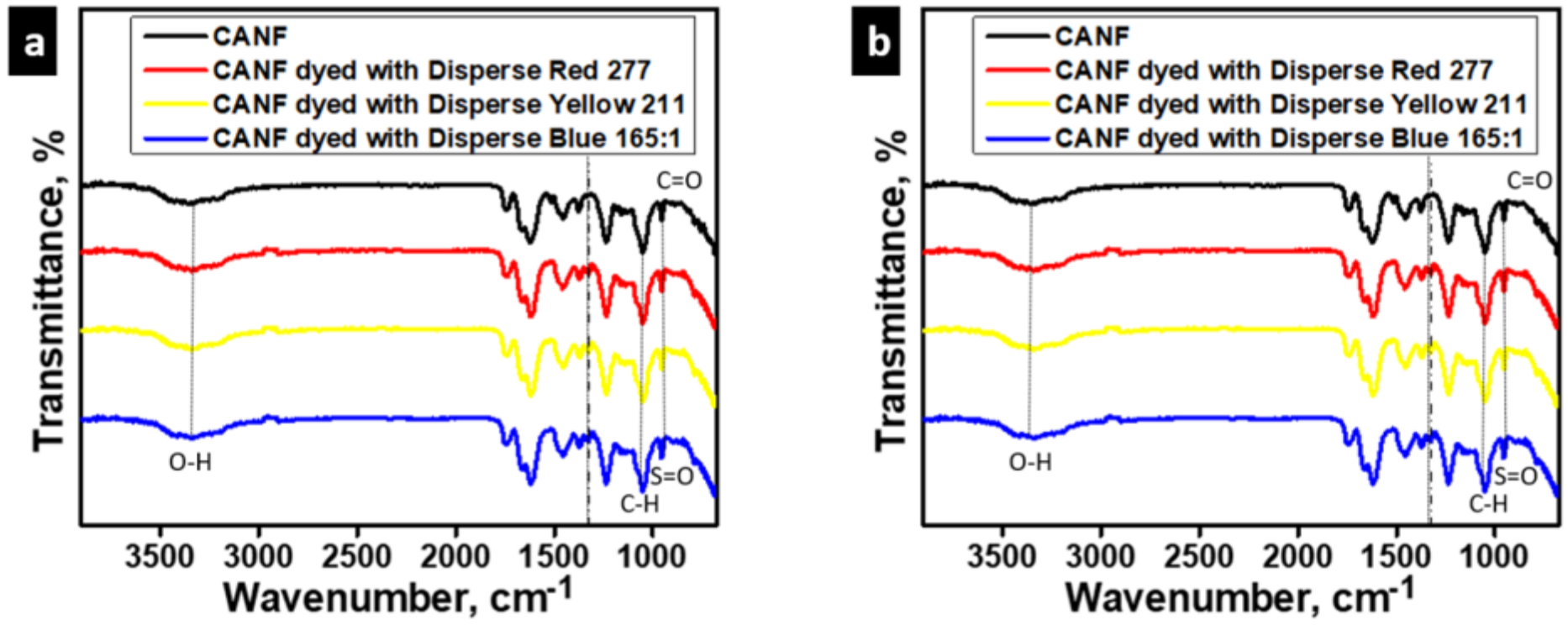

Figure 11

FTIR spectra of pure and dyed CANF with CI Disperse Red 277, Cl Disperse Yellow 211 and Cl Disperse Blue 165:1 in (a) CC:EG media and (b) CC:Urea media 

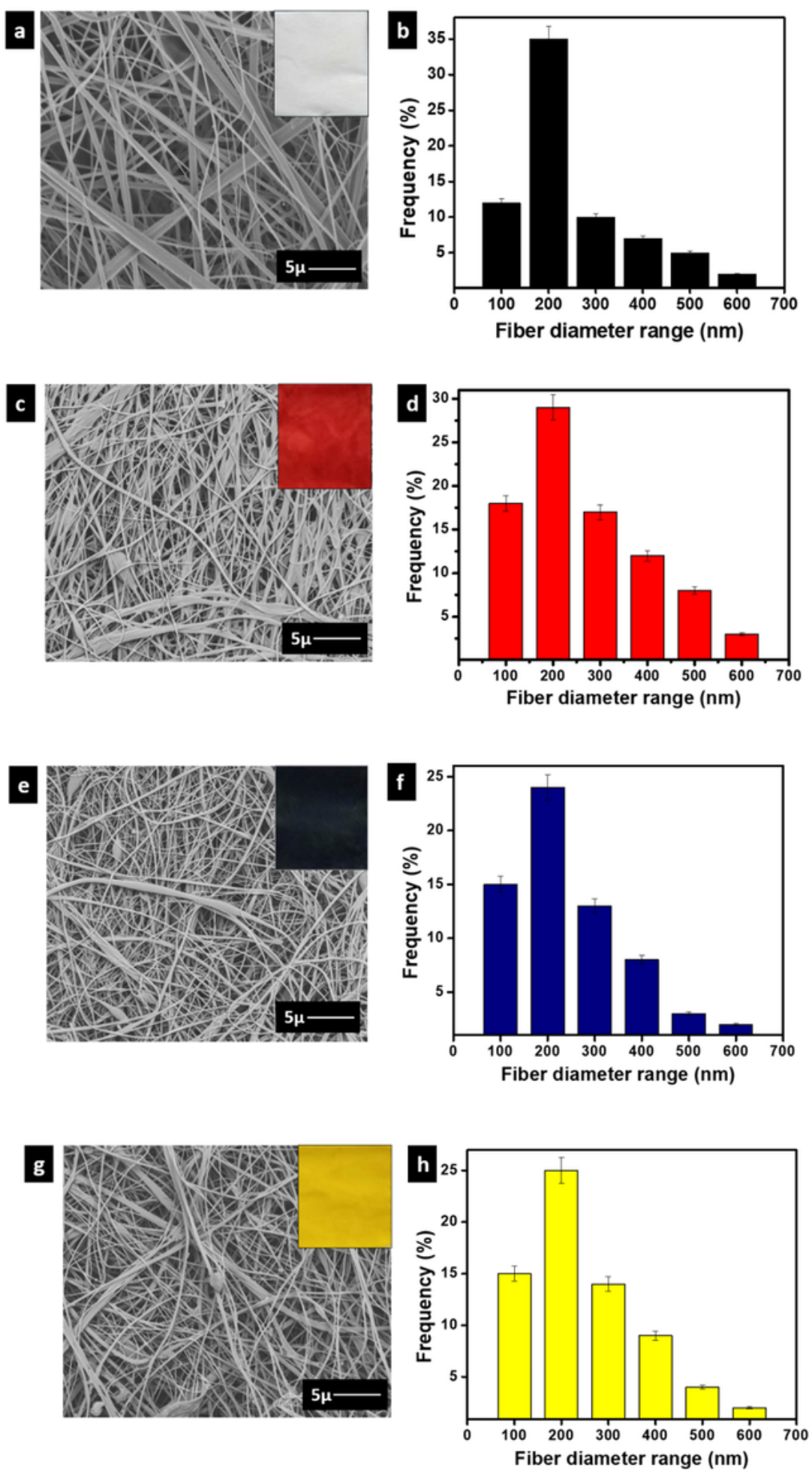

Figure 12

The SEM images and diameter distribution histograms of CANF (a-b) pure CANF and dyed in CC:EG media (c-d) Cl Disperse Red 277 (e-f) Cl Disperse Blue 165:1 (g-h) Cl Disperse Yellow 211 
i

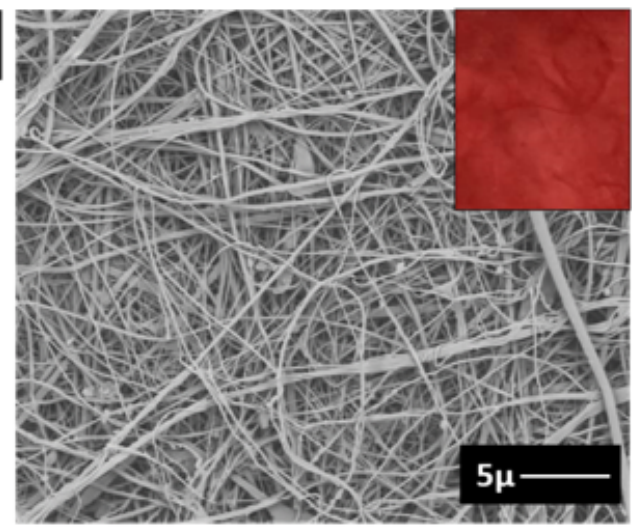

k

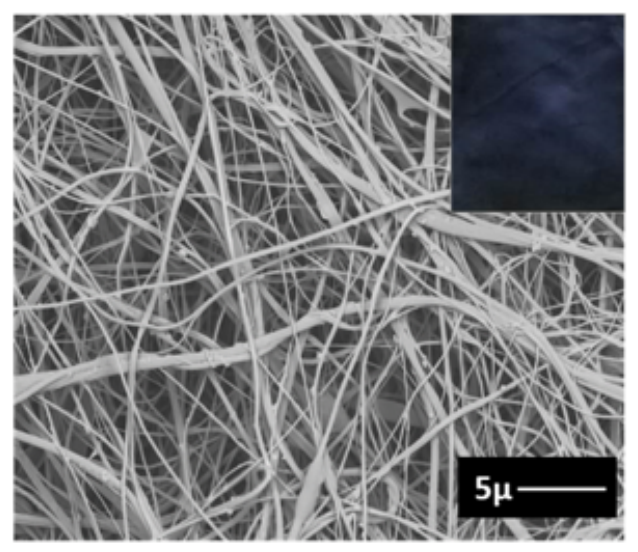

m

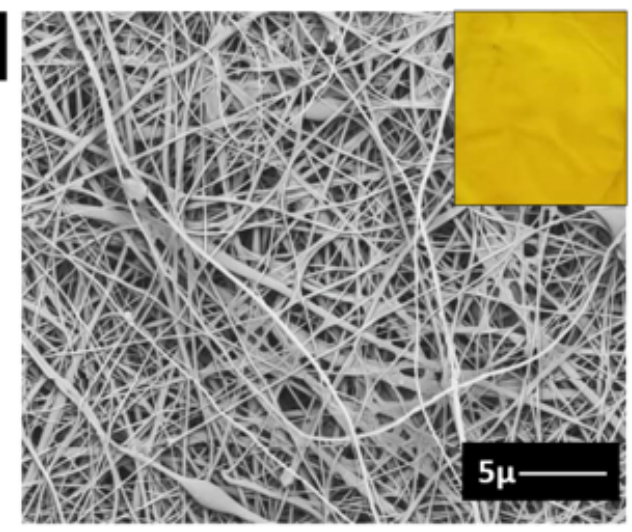

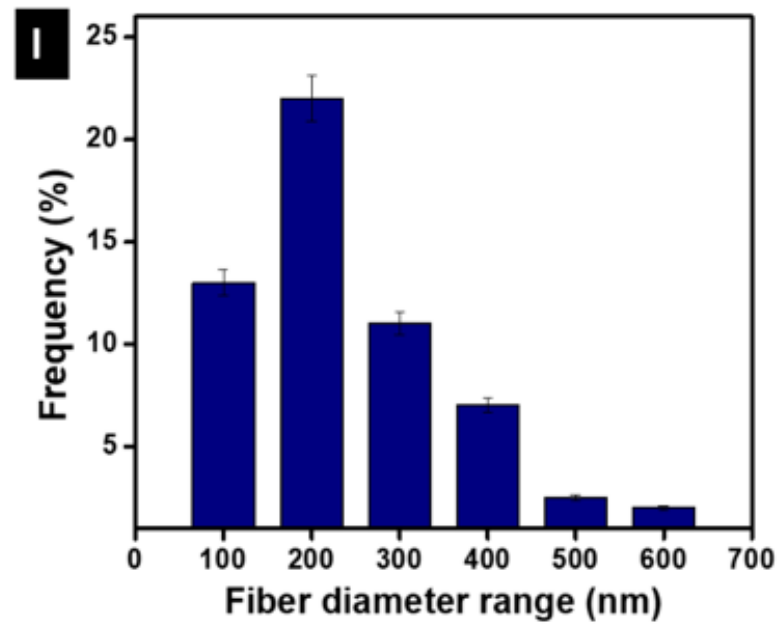
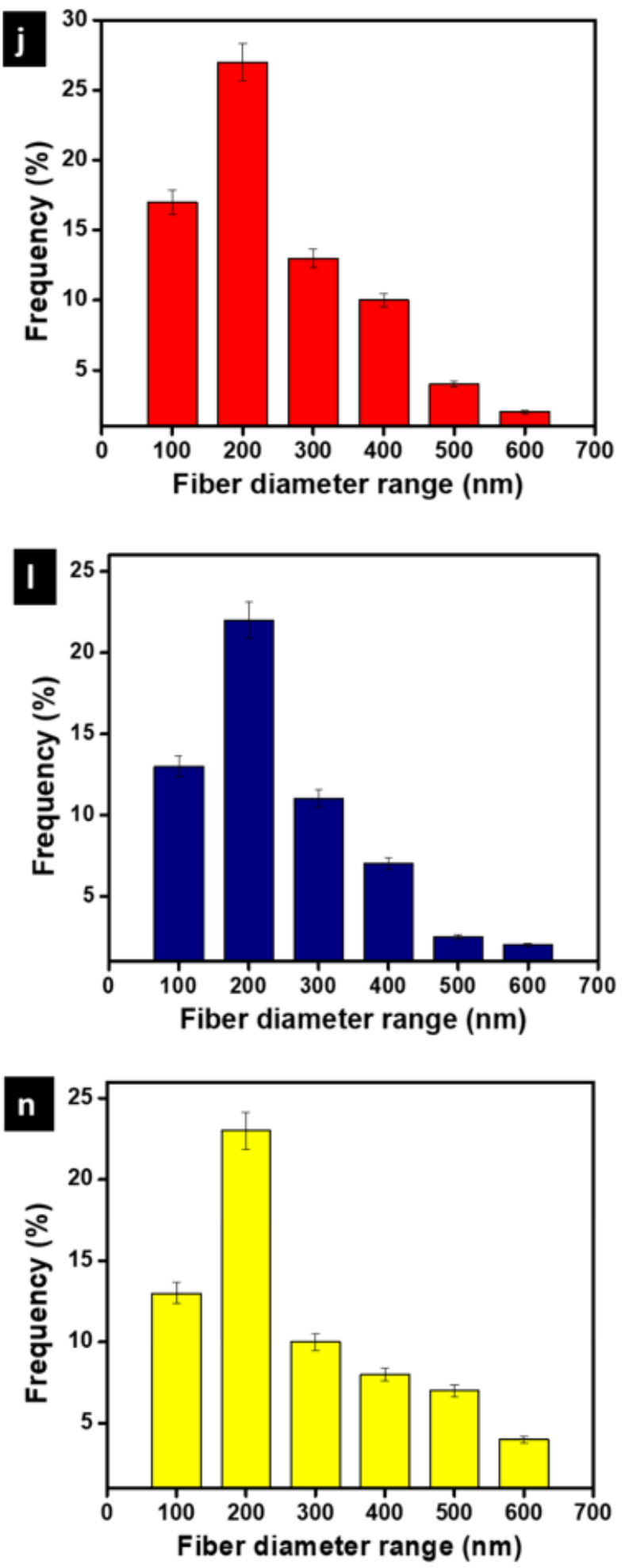

Figure 13

The SEM images and diameter distribution histograms of CANF dyed in CC:Urea media (i-j) CI Disperse Red 277 (k-l) Cl Disperse Blue 165:1 (m-n) Cl Disperse Yellow 211

\section{Supplementary Files}


This is a list of supplementary files associated with this preprint. Click to download.

- GraphicalAbstract.png 